\title{
Preparation of Mesoporous Silicon Carbide from Nano-Sized SiC Particle and Polycarbosilane
}

\author{
Manabu FUKUSHIMA, You ZHOU, Yu-ichi YOSHIZAWA, Hiroyuki MIYAZAKI and Kiyoshi HIRAO \\ National Institute of Advanced Industrial Science and Technology (AIST), \\ 2266-98, Shimo-Shidami, Moriyama-ku, Nagoya-shi, Aichi 463-8560
}

\author{
ポリカルボシランとナノ粒子によるメソポーラス炭化ケイ素の作製 \\ 福島 学 ·周 游·吉澤友一·宮崎広行 ·平尾喜代司 \\ 独立行政法人産業技術総合研究所先進製造プロセ久研究部門，463-8560 名古屋市守山区下志段味穴ヶ洞 2266-98
}

\begin{abstract}
Mesoporous silicon carbide ( $\mathrm{SiC}$ ) ceramics were produced via the pyrolysis of polycarbosilane (PCS) with and without SiC nano sized particle filler, and their pore characteristics such as size and BET surface area were investigated. The amount of filler and the pyrolysis temperature significantly affected the surface area and pore size. The surface area of PCS reached around $0.5 \mathrm{~m}^{2} / \mathrm{g}$ by the pyrolysis at $800^{\circ} \mathrm{C}$ and pore also was found to almost disappear. In contrast, the specimen with filler showed high surface area above $200 \mathrm{~m}^{2} / \mathrm{g}$ after the pyrolysis at $800^{\circ} \mathrm{C}$ and the retention of mesopore even after the pyrolysis at $1200^{\circ} \mathrm{C}$.
\end{abstract}

[Received January 31, 2006; Accepted March 16, 2006]

Key-words : Silicon carbide, Mesoporous, Surface area, Membrane and pore size distribution

1. Introduction

Porous silicon carbide $(\mathrm{SiC})$ ceramics have been widely used as filter and catalyst support because $\mathrm{SiC}$ has a good thermal stability as well as excellent mechanical properties. In porous products, porosity, pore size distribution and surface area are very important properties which affect the various characteristics such as gas permeation and the capturing of particulate. The porous products are generally categorized by their pore size as three kinds of materials: macroporous $(\Phi>$ $50 \mathrm{~nm})$, mesoporous $(2 \mathrm{~nm}<\Phi<50 \mathrm{~nm})$ and microporous $(\Phi<2 \mathrm{~nm})$. The macroporous ceramics can be fabricated by the partial liquid phase sintering with slight additive or the oxidation bonding among particles or recrystallization methods. ${ }^{1)-6)}$ The macroporous $\mathrm{SiC}$ has been used as membrane support ${ }^{4)-6)}$ and diesel particulate filter (DPF). ${ }^{7)}$ On the other hand, silicon-carbon based microporous or mesoporous ceramics are prepared by the pyrolysis of precursor polymer. ${ }^{8)-10)}$ The typical precursor polymers are the gel derived from the hydrolysis and condensation of organically modified silicon alkoxide, and/or the organic polymer such as polycarbosilane. These polymer precursors are very important raw materials, since it is difficult for the normal sintering route of fine particles to provide micro- or meso pore.

The micro- or meso- porous ceramics have recently gathered much attention as the environmental equipments such as hydrogen permselective membrane and purification of filthy water, because the ceramic materials have the better properties of chemical/thermal stability and corrosive resistance than those of organic materials. In the above mentioned applications, the components are often exposed to high temperature steam (the steam disinfection and the hydrogen production by the steam modification of natural gas). SiC has a low selfdiffusion coefficient and superior thermal shock resistance among various ceramic materials, which make $\mathrm{SiC}$ a promising candidate material for above mentioned applications.

In the fabrication of micro- or meso- porous $\mathrm{SiC}$, pyrolysis of silicon-carbon based precursor is a popular way, and this process is already accompanying by gas evolution and volume changing. Seen from the previous reports, hydrogen, hydrocarbon and silane are released during pyrolysis, which are found to occur below $1300^{\circ} \mathrm{C} .{ }^{11)-14)}$ However, when these precursor polymers are heated above $1300^{\circ} \mathrm{C}$, the micro or meso pore may be difficult to obtain because crystallization to $\beta$-SiC occurs. ${ }^{15), 16)}$ Thus, in controlling the pore size of ceramic derived from polymer precursors, the pyrolysis temperature of precursor is found to be important. ${ }^{17)}$

In the preparation of porous products, the various kinds of additive as filler (active or inert), pore forming agent and foaming chemical have often been used. These additives are found to affect the pore shape and size of resultant material as well as surface area. ${ }^{17)}$ In addition, the filler can improve the mechanical properties as reinforcement and decrease the large volume changing.

These previous studies suggest that the factors such as filler, its content and pyrolysis temperature can greatly affect the properties of porous SiC. However, these effects have not been systematically investigated; in particular, the relationship between filler, pyrolysis temperature and properties has not been sufficiently clarified. In this communication, the preparation of mesoporous silicon carbide $(\mathrm{SiC})$ that possesses a variable surface area was attempted and its pore formation was investigated.

\section{Experimental procedure}

\subsection{Sample preparation}

Polycarbosilane (PCS, Type UH; Nippon Carbon Co., Ltd., Tokyo) was used as a precursor polymer. High purity $\beta$-SiC powder (Sumitomo Osaka Cement Co., Ltd., Tokyo) with an average particle size of $30 \mathrm{~nm}$ and a specific surface area of $40-50 \mathrm{~m}^{2} / \mathrm{g}$ was used as a filler. The particle produced from plasma CVD method was almost found to be spherical shape. The main impurities in the nano-sized $\mathrm{SiC}$ powder were 1.8-2.4 mass\% carbon and $0.3-0.6$ mass\% oxygen. These mixtures with the weight ratios of 0.44 and $0.62=\mathrm{SiC} /(\mathrm{PCS}$ $+\mathrm{SiC}$ ) were blended in toluene for $2 \mathrm{~h}$ using a planetary mill with a $\mathrm{SiC}$ pot and $\mathrm{SiC}$ balls. Hereafter, these compositions 
are referred to $\mathrm{SiC} 44$, and $\mathrm{SiC62}$, respectively, according to the $\mathrm{SiC}$ content. As reference, the powder specimens of pure PCS and pure SiC filler were used. After mixing, the slurry was cast on the Teflon dish and then dried under ambient atmosphere. The green samples without any oxidation were placed in a quartz or graphite dish and heated at 600,800 and $1200^{\circ} \mathrm{C}$ for $2 \mathrm{~h}$ under $\mathrm{Ar}$ gas flowing. The heating rate from room temperature to setting temperatures was $3^{\circ} \mathrm{C} / \mathrm{min}$ and the holding time was $2 \mathrm{~h}$.

\subsection{Characterization}

The specific surface area of prepared porous samples was characterized by nitrogen adsorption measurements (Yuasa Ionics Inc., Autosorb, Osaka). BET surface area was determined from a BET (Brunauer, Emmet and Teller) analysis in the $P / P_{0}$ range of $0.05-0.30$ using a molecular cross sectional area for $\mathrm{N}_{2}$ of $0.163 \mathrm{~nm}^{2}$ and multi points. The pore size (below $50 \mathrm{~nm}$ ) was determined by desorption isothermal plot using Barrett-Joyner-Halenda (BJH) method. The microstructures of the specimens were observed by optical microscopy and scanning electron microscopy (SEM; JEOL-6330F, Tokyo).

\section{Results and discussion}

Figure 1 shows the optical microscope of the pyrolyzed specimens (A) SiC44 (with filler) and (B) pure PCS (without filler). As seen from the observations, their morphologies were found to be significantly different. This clearly suggests that the surface morphology after pyrolysis was affected by the filler. While bubbles and wrinkles on the pyrolyzed pure PCS specimen were monitored, the addition of filler was found to prevent these phenomena and provide smooth surface. It seemed that the pure PCS during pyrolysis was bloated by the fast heating rate and mass loss in the case without preoxidation. ${ }^{18)}$ In general, the preparation of precursor derived ceramic is accompanied with gas evolution, and the present result about pure PCS is also thought to be connected with the gas evolution during pyrolysis.

Figure 2 shows the $\mathrm{H} / \mathrm{C}$ ratio of pure PCS and SiC62 as a function of pyrolysis temperature. The ratio of SiC62 specimen was calculated for the part of contained PCS. The H/C ratio of both specimens decreased with increasing pyrolysis temperature, which is due to the gas evolution during pyrolysis. Seen from the previous reports, the low-molecular gas as hydrogen and hydrocarbon is found to evolve above $400^{\circ} \mathrm{C}^{19)}{ }^{20)}$ The evolution of these gas species is accompanied with the consumption of hydrogen, corresponding to the decreasing of $\mathrm{H} / \mathrm{C}$ ratio.

Figure 3 shows the specific surface area of the pyrolyzed samples versus pyrolysis temperature in the range of $600-$ $1200^{\circ} \mathrm{C}$. The surface area of pure PCS and the specimens with filler showed the maximum values at the heating temperature of $600^{\circ} \mathrm{C}$. The surface area of the specimens with filler gradually decreased with increasing pyrolysis temperature. In contrast, the surface area of the pure PCS dramatically decreased and reached around $0.5 \mathrm{~m}^{2} / \mathrm{g}$ at $800^{\circ} \mathrm{C}$, which were consistent with the previous report. ${ }^{9)}$ That of pure $\mathrm{SiC}$ did not show any change. Namely, the addition of filler was found to affect the retention of high surface area.

On the other hand, the content of filler also affected the surface area. The higher content of filler resulted in the decrease of the surface area. When the surface area of filler itself is assumed to be unchanged value, the part of PCS in the specimen with filler has an important role to enlarge the surface area.

In addition to the pyrolysis temperature and the filler con-
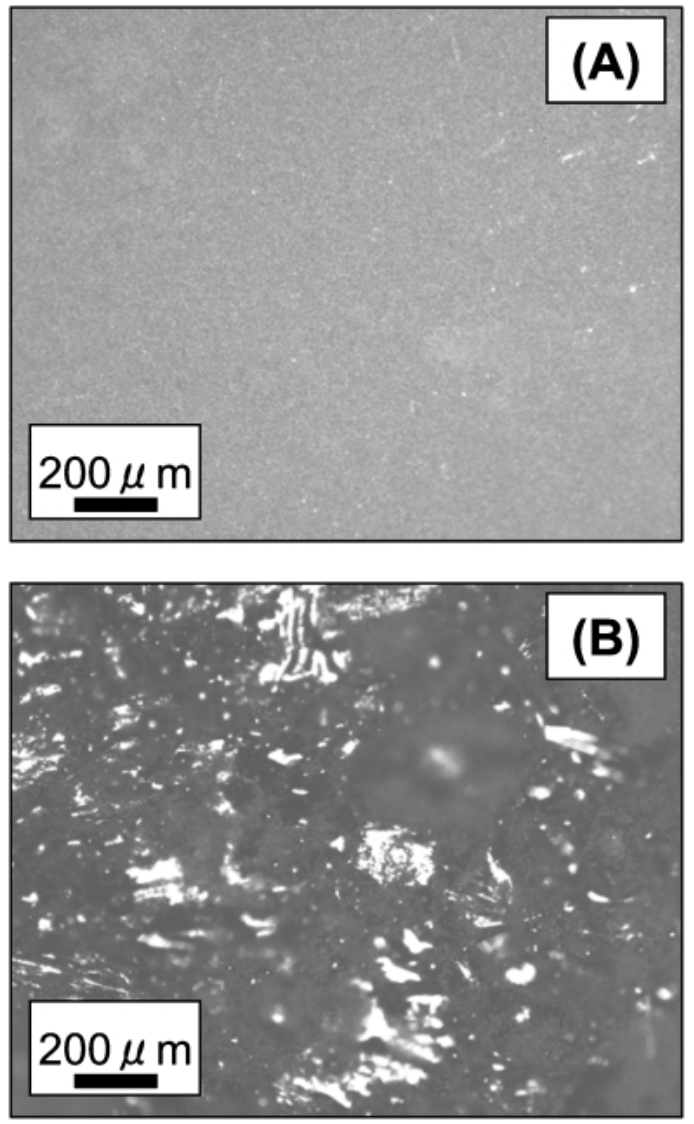

Fig. 1. Optical micrographs of the pyrolyzed specimens (A) SiC44 and (B) pure PCS at $600^{\circ} \mathrm{C}$.

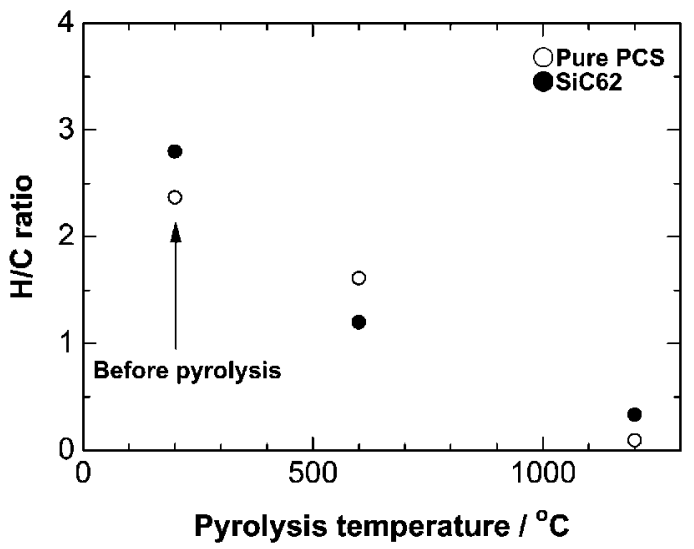

Fig. 2. H/C ratio of pure PCS and SiC62 specimens as a function of pyrolysis temperature.

tent, the dimensional changes were also related with the addition of filler. The pyrolyzed pure PCS powder showed large expansion at $600^{\circ} \mathrm{C}$ (though this was hardly measurable, the linear changes above $20 \%$ were found), which is due to gas evolution and heating rate. In contrast, the SiC44 specimens showed the slight shrinkage around 8 and $10 \%$ at 600 and $800^{\circ} \mathrm{C}$, respectively. This indicates that the filler could prevent the dimensional change by the presence of solid phase and provide the channel for the evolved gas. Thus, the dimensional changes do not significantly occur and the low-molecular gas such as hydrocarbon is evolved through channel, which result 


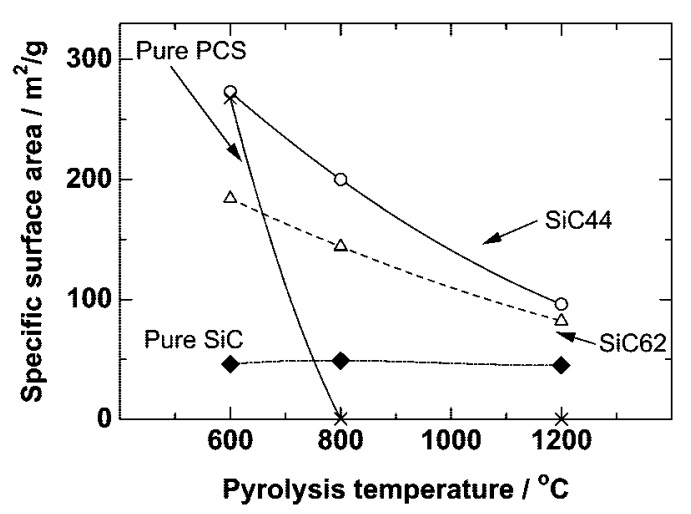

Fig. 3. Specific surface area of the pyrolyzed samples versus pyrolysis temperature in the range of $600-1200^{\circ} \mathrm{C}$.

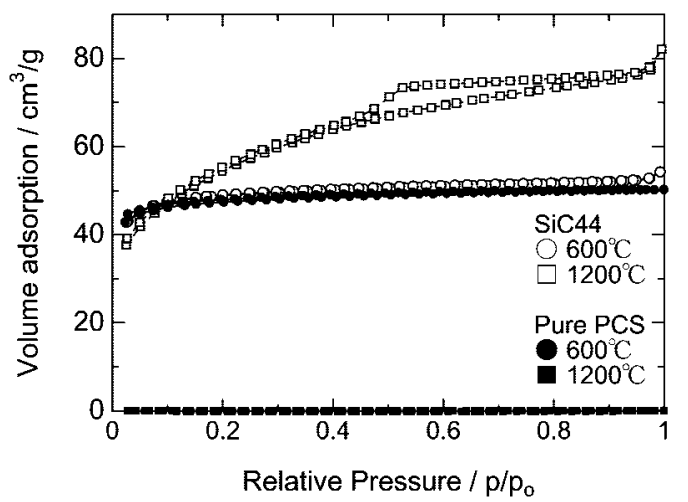

Fig. 4. Isotherms of the SiC44 and pure PCS specimen pyrolyzed at different temperatures.

in the formation of the fine pores by the evolved gas and their retention.

$\mathrm{N}_{2}$ gas adsorption and desorption can show the properties of pore and surface area. The isotherms of SiC44 and pure PCS specimen pyrolyzed at different temperatures are illustrated in Fig. 4. The increasing at low relative pressure (SiC44 and pure PCS pyrolyzed at $600^{\circ} \mathrm{C}$ ) and the slight hysteresis loops in the range of relative pressure between 0.4 and 0.6 (SiC44 pyrolyzed at $1200^{\circ} \mathrm{C}$ ), namely type I and IV isotherms were monitored. The increasing at low relative pressure indicates the presence of micropore, while the hysteresis loops mean the existence of mesopores. As seen from the result, the pyrolysis temperature is found to affect the pore characteristics. The isotherm of SiC44 specimen was varied from type I to IV, meaning the retention of mesopore even after pyrolysis at $1200^{\circ} \mathrm{C}$. In contrast, any adsorption in PCS pyrolyzed at $1200^{\circ} \mathrm{C}$ was not monitored, which was consistent with the result of Fig. 3. This means the disappearance of pore by the pyrolysis. Thus, also in Fig. 4, the effect of the filler connected pore characteristics was monitored.

Figure 5 shows the BJH desorption pore size distributions of the pyrolyzed SiC44 and pure PCS specimens at various temperatures. Seen from the result of SiC44 specimen, the sharp peak around $4 \mathrm{~nm}$ was detected. In addition, the peak below $4 \mathrm{~nm}$ was also found to exist, suggesting the possibility of the existence of micropore. The pore size did not significantly change and was retained, regardless of the pyrolysis temperature. In contrast, the pore of the pyrolyzed pure PCS

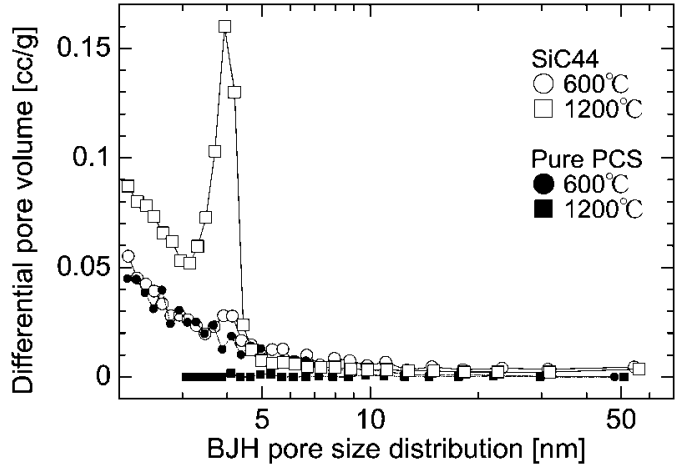

Fig. 5. BJH desorption pore size distributions of the pyrolyzed $\mathrm{SiC} 44$ and pure PCS specimens at various temperatures.

at $1200^{\circ} \mathrm{C}$ was not monitored, which was corresponding to the degradation of surface area.

The monitored pore in SiC44 specimen may be the channel of the evolved gas during the pyrolysis of PCS. In contrast, pure PCS specimen did not possess the pore (in other words, like of channels for gas evolution). That is to say, the gas species were firstly blocked inside the specimen without channel and then, with the further increasing of temperature, they expanded and caused the formation of bubbles and wrinkles in the final pyrolyzed body.

As above mentioned, the pure PCS pyrolyzed above $800^{\circ} \mathrm{C}$ showed the disappearance of pore, resulting in the significant decreasing of surface area. Seen from the previous report, when the lower pyrolysis temperature around $400-500^{\circ} \mathrm{C}$ is applied for pure PCS, surface area above $500 \mathrm{~m}^{2} / \mathrm{g}$ is found to obtain. ${ }^{9)}$ This temperature range is corresponding to the beginning of gas evolution from PCS, ${ }^{20)}$ which suggests that the pore is formed around $400-500^{\circ} \mathrm{C}$. Since the dimensional change around this range is less than that around $600-800^{\circ} \mathrm{C}$, the space by gas evolution is directly connected with the pore formation. However, the pore of pure PCS disappears at around $600-800^{\circ} \mathrm{C}$, resulting in the significant decrease of surface area. On the other hand, the addition of filler prevented the disappearance of pore and retained its size even after pyrolysis at $1200^{\circ} \mathrm{C}$. The amount of formed pore at $400-500^{\circ} \mathrm{C}$ may be corresponding to the content of PCS in the specimen with the filler. Thus, the larger PCS content is considered to results in higher surface area, because the formation of pore is due to the pyrolysis of PCS part in the specimen with filler.

Figure 6 shows the FE-SEM micrographs of the pyrolyzed SiC44 specimens. In the micrograph, the pyrolyzed PCS was filled among nano sized $\mathrm{SiC}$ particles. From the results of surface area and pore size distribution, the filled PCS between particles may possess the mesopore due to the evolved gas during pyrolysis.

\section{Conclusion}

The pore size and specific surface area of silicon carbide derived from polycarbosilane and nano sized $\mathrm{SiC}$ particle filler were investigated. The pyrolysis temperature and the filler had tremendous effects on pore size and surface area. The addition of filler resulted in the retention of mesopores even after the pyrolysis at $1200^{\circ} \mathrm{C}$, while the pores of pyrolyzed PCS almost disappeared.

References

1) She, J. H., Yang, J. F., Kondo, N., Ohji, T. and Kanzaki, S., J. 


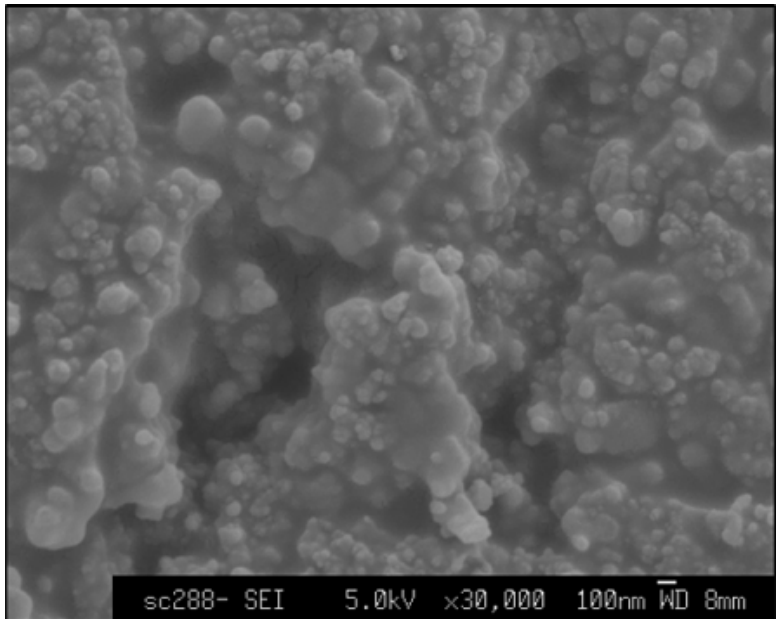

Fig. 6. FE-SEM micrographs of the SiC44 specimens pyrolyzed at $800^{\circ} \mathrm{C}$.

Am. Ceram. Soc., Vol. 85, pp. 2852-2854 (2002).

2) Yang, J. F., Zhang, G. J., Kondo, N., She, J. H., Jin, Z. H., Ohji, T. and Kanzaki, S., J. Am. Ceram. Soc., Vol. 86, pp. 910-914 (2003).

3) She, J. H., Ohji, T. and Kanzaki, S., J. Eur. Ceram. Soc., Vol. 24, pp. 331-334 (2004).

4) Lin, P.-K. and Tsai, D.-S., J. Am. Ceram. Soc., Vol. 80, pp. 365-372 (1997).

5) Suwanmethanond, V., Goo, E., Liu, P. K. T., Johnston, G., Sahimi, M. and Tsotsis, T. T., Ind. Eng. Chem. Res., Vol. 39, pp. 3264-3271 (2000).
6) Fukushima, M., Zhou, Y., Iwamoto, Y., Yamazaki, S., Nagano, T., Miyazaki, H., Yoshizawa, Y. and Hirao, K., $J$. Am. Ceram. Soc. (accepted).

7) O'Sullivan, D., Pomeroy, M. J., Hampshire, S. and Murtagh, M. J., J. Mater. Res., Vol. 19, pp. 2913-2921 (2004).

8) Sea, B.-K., Kusakabe, K. and Morooka, S., J. Membr. Sci., Vol. 130, pp. 41-52 (1997).

9) Li, Z., Kusakabe, K. and Morooka, S., J. Membr. Sci., Vol. 118, pp. 159-168 (1996).

10) Zahir, M. H., Sato, K. and Iwamoto, Y., J. Membr. Sci., Vol. 247, pp. 95-101 (2005).

11) Fukushima, M., Yasuda, E., Nakamura, Y., Kita, H., Kawabata, H. and Tanabe, Y., J. Ceram. Soc. Japan, Vol. 113, pp. 210-215 (2005).

12) Fukushima, M., Yasuda, E., Nakamura, Y. and Tanabe, Y., $J$. Ceram. Soc. Japan, Vol. 110, pp. 857-859 (2003).

13) Belot, V., Corriu, R. J. P., Leclercq, D., Mutin, P. H. and Vioux, A., J. Non-Cryst. Solids, Vol. 144, pp. 287-297 (1992).

14) Kamiya, K., Yoko, T., Tanaka, K. and Takeuchi, M., J. NonCryst. Solids, Vol. 121, pp. 182-187 (1990).

15) Sugahara, Y., Takeda, Y., Kuroda, K. and Kato, C., J. Mat. Sci. Lett., Vol. 8, pp. 944-946 (1989).

16) Narisawa, M., Okabe, Y., Okamura, K. and Kurachi, Y., $J$. Ceram. Soc. Japan, Vol. 107, pp. 285-289 (1999).

17) Schmidt, H., Koch, D., Grathwohl, G. and Colombo, P., J. Am. Ceram. Soc., Vol. 84, pp. 2252-2255 (2001).

18) Danko, G. A., Silberglitt, R., Colombo, P., Pippel, E. and Woltersdorf, J., J. Am. Ceram. Soc., Vol. 83, pp. 1617-1625 (2000).

19) Soraru, G. D., Babonneau, F. and Mackenzie, J. D., J. Mat. Sci., Vol. 25, pp. 3886-3893 (1990).

20) Narisawa, M., Shimoda, M., Okamura, K., Sugimoto, M. and Seguchi, T., Bull. Chem. Soc. Jpn., Vol. 68, pp. 1098-1104 (1995). 